\title{
8-isorpostanes - markers for oxidative stress in obstructive sleep apnea patients with systolic dysfunction
}

This article was published in the following Dove Press journal:

Research Reports in Clinical Cardiology

19 June 2013

Number of times this article has been viewed

\section{Radostina Vlaeva Cherneva' Ognian Borisov Georgiev' Daniela Stoichkova Petrova' Emil Ivanov Manov ${ }^{2}$ Sylvia Rumenova Ruseva ${ }^{3}$ Vanio Ivanov Mitev ${ }^{3}$ Julia Ivanova Petrova ${ }^{4}$}

'Department of Internal Medicine, Division of Pulmonary Medicine, Medical University of Sofia, Sofia, Bulgaria; ${ }^{2}$ Department of Internal Medicine, Division of Cardiology, Medical University of Sofia, Sofia, Bulgaria; ${ }^{3}$ Department of Medical Chemistry and Biochemistry, Laboratory of Synthesis and Analysis of Bioactive Substances, Medical University of Sofia, Sofia, Bulgaria; ${ }^{4}$ Department of Neurology, Medical University of Sofia, Sofia, Bulgaria
Correspondence: Radostina Vlaeva Cherneva

Division of Pulmonary Medicine, Medical University of Sofia,

|43| Georgi Sofiiski St, Sofia, Bulgaria

Tel +359888 512 9402

Email cherneva_radost@yahoo.com
Objective: Increased oxidative stress is considered to be an independent risk factor for cardiovascular diseases, but remains disputed in obstructive sleep apnea (OSA). Among oxidative stress markers, isorpostanes are considered to be the most sensitive and specific.

Aims: The aim of the study was to compare urinary isorpostanes in patients with OSA and systolic dysfunction to patients with OSA and preserved ejection fraction (EF) and determine their role as markers for increased oxidative stress and early cardiac damage.

Materials and methods: Urinary 8F2-isorpostanes were measured in 30 patients with OSA and mild systolic dysfunction ( $\mathrm{EF}=45.7 \% \pm 6.17 \%$ ) and compared to 15 patients with OSA and normal $\mathrm{EF}(\mathrm{EF}=60.3 \% \pm 6.3 \%)$. Univariate regression analysis was performed to find predictors of left systolic dysfunction. Correlations between 8-isorpostanes, anthropometric, metabolic, and sleep study characteristics were explored. In addition, in 19 patients the effect of bilevel positive airway pressure (BiPAP) therapy was evaluated during a 3 month follow-up. Markers of hemodynamic stress, N-terminal prohormone of brain natriuretic peptide and oxidative stress, measured by 8 -isorpostanes were compared before and after the follow-up.

Results: Urinary levels of 8-isorpostanes were significantly higher in the group with mild systolic dysfunction in comparison to the controls with preserved EF $(0.149$ versus $0.049 \mathrm{pg} / \mu \mathrm{L}$, $P=0.023)$. The regression analysis did not define them as predictors for left systolic dysfunction. Their urinary concentration correlated best to the average desaturation index $(P=0.043)$. Urinary 8 -isorpostanes decreased as a result of BiPAP therapy after three months of follow-up $(0.164$ versus $0.098 \mathrm{pg} / \mu \mathrm{L}, P=0.011$ ).

Conclusion: Urinary isorpostanes are reliable markers for chronic intermittent hypoxia and oxidative stress in OSA patients. They may be of clinical application for the early detection of patients at risk for cardiovascular damage and could help in the monitoring of the restoration of oxidative balance.

Keywords: 8-isorpostanes, oxidative stress, LV systolic dysfunction, OSA

\section{Introduction}

Cardiovascular risk is undoubtedly increased in obstructive sleep apnea (OSA) patients. The main triggers are supposed to be due to accelerated recurrent hypoxia, hypercapnia, acidosis, increased sympathetic activity, and impairment of the balance between myocardial oxygen demand and supply during sleep. ${ }^{1,2}$ The accompanying metabolic syndrome, adipose tissue dysfunction, and dysregulated adipokine secretion additionally contribute to the oxidative stress these patients are exposed to. ${ }^{3-5}$

Chronic intermittent hypoxia, characteristic for sleep disordered breathing is a prominent feature of OSA. Patients with OSA experience episodes of cessation 
of breathing, which lead to hypoxia and reoxygenation. ${ }^{6,7}$ These events may represent a form of oxidative stress, leading to increased generation of reactive oxygen species, that expose this group of patients to prolonged vascular and cardiac damage. Consequently, OSA has recently been described as an oxidative stress disorder in which oxygen-free radicals, produced within the vasculature, activate leukocytes, cause lipid peroxidation, and cause adhesion molecule expression and inflammation - mechanisms, promoting cardiovascular derangements. ${ }^{8,9}$ However, due to different biochemical markers and technical approaches, the presence of oxidative stress in OSA patients has long been disputed. ${ }^{10,11}$ The recent application of mass spectrometry validated isorpostanes as the "gold standard," for measuring lipid peroxidation in vivo. ${ }^{12,13}$ Urinary isorpostanes in OSA patients have been reported as markers for early vascular remodeling preceding functional impairment. ${ }^{14}$

Considering this and assuming the fact that oxidative stress is correlated with the progression of heart failure ${ }^{15,16}$ and deterioration of functional capacity, ${ }^{17}$ we tried to evaluate the clinical usefulness of urinary isorpostanes as markers for oxidative stress and early cardiac damage in OSA patients.

\section{Materials and methods Subjects}

Forty-five patients with newly diagnosed OSA participated in the study. Patients were recruited from the Sleep Lab of the University Hospital "Alexandrovska," Clinic of Internal Medicine, Division of Pulmonology during the period January-April 2011. Fifteen patients with preserved EF were included in the control group. The rest of the patients had mild systolic dysfunction. To establish the effect of bilevel positive airway pressure (BiPAP) therapy they have been followed up for 3 months. The study was approved by the Ethics Committee of the Medical University of Sofia. All patients signed informed consent forms for participation.

\section{Inclusion criteria}

Inclusion criteria were ejection fraction $(\mathrm{EF})<50 \%$ and stable chronic heart failure. During the last 3 months patients had not been hospitalized and had not changed their supportive therapy. The diagnosis of OSA was based on a combination of clinical symptoms (ie, daytime excessive sleepiness) and a standard polysomnography (E-series; Compumedics Limited, Victoria, Australia). OSA was considered if the apnea-hypopnea index (AHI) was more than five events per hour.

\section{Exclusion criteria}

Exclusion criteria were as follows: (1) long-term continuous positive airway pressure (CPAP) or BiPAP therapy; (2) central sleep apnea or Cheyne-Stokes respiration; (3) chronic obstructive pulmonary disease, chronic respiratory failure, or need of oxygen therapy; (4) ischemic episode or unstable angina; (5) recent episode of acute heart failure within the last 6 months; (6) concomitant large hemispheric or brainstem stroke; (7) renal failure; and (8) neoplasm.

\section{Study design}

Patients with systolic dysfunction and OSA were recruited after baseline polysomnography. Patients were provided with the same positive airway pressure (PAP) device (BiPAP-ST, DeVilbiss, Somerset, PA, USA). Those who agreed to remain on noninvasive ventilation formed the BiPAP treatment modality group. Those who refused noninvasive ventilation remained on their current pharmacotherapy. The cardiologist performing echocardiography was blinded to patient assignment. The use of the same machine protected against any bias regarding superiority of any device that participants may have had. The research coordinators contacted participants monthly and received their device card memory.

\section{Clinical methods}

\section{Polysomnography}

Baseline polysomnography was standard nocturnal polysomnography performed in the Sleep Laboratory. The polysomnography included airflow measured by nasal airflow; thoracoabdominal wall movements were measured by inductance plethysmography; arterial oxygen saturation was measured by pulse oximetry; electrocardiogram, bilateral electrooculography, four channels of electroencephalography, body position was detected and chin and tibial electromyograms were also performed.

Scoring of respiratory events in the polysomnography was according to the definitions provided by the American Academy of Sleep Medicine. ${ }^{18}$ Continuous positive pressure was used for all patients on the titration night and the titrationtargeted elimination of apneas was performed.

\section{Echocardiography}

All participants underwent resting two-dimensionally guided M-mode echocardiography at baseline. Left ventricle (LV) 
septal wall thickness, posterior LV wall thickness, and LV end-diastolic diameter were measured at end-diastole. LV end-systolic diameter and left anterior descending were measured at end-systole. All measurements were obtained in accordance with the American Society of Echocardiography guidelines using a leading-edge-to-leading-edge technique. ${ }^{19}$ LV fractional shortening was calculated as (LV end-diastolic diameter - LV end-systolic diameter)/(LV end-diastolic diameter). LV EF was measured according to the modified Simpson's method. The echocardiographer was blinded to device randomization.

\section{4-hour blood pressure monitoring}

Blood pressure monitoring was performed with Boso, (ProfilManager, Bosch and Sohn, GmbH Co.KG Jungingen, Germany). Blood pressure was recorded every 20 minutes during the daytime (between 7 am and $10 \mathrm{pm}$ ) and every 30 minutes during the nighttime (between $10 \mathrm{pm}$ and $7 \mathrm{am}$ ) for 24 hours. Patients recorded a daily action profile from which information about the precise times of sleeping and waking were obtained. The onset of sleep was identified as the time that the participant went to bed. The participants were instructed to carry out normal daily activities during the monitoring period.

\section{Laboratory assays}

$\mathrm{N}$-terminal prohormone of brain natriuretic peptide (NT-pro-BNP)

Plasma levels of NT-pro-BNP were determined by electrochemiluminescence immunoassay for quantitative determination (Elecsys proBNP II assay, Roche, Basel, Switzerland). Functional sensitivity was $0.6-4130 \mathrm{pmol} / \mathrm{L}$. The coefficient of variation was $20 \%$.

\section{Urinary 8-isorpostanes levels}

The levels of 8-isorpostanes in urine samples were determined by high resolution accurate mass (HRAM) mass spectrometry on an LTQ Orbitrap ${ }^{\circledR}$ Discovery (Thermo Fisher Scientific, Waltham, MA, USA) mass spectrometer, equipped with a Surveyor $^{\circledR}$ ESI module (ThermoScientific Co, USA), Plus high-performance liquid chromatography system and IonMax ${ }^{\circledR}$ (ThermoScientific Co, USA) electrospray ionization module. The analyses were carried out by the stable isotope dilution method in negative ionization mode using heated electrospray ionization (HESI-II) source type. The concentration and purification of 8-isorpostanes from urine samples was processed by affinity sorbent (Cayman Chemical, Ann Arbor,
MI, USA), following the producer's protocol. The urinary isorpostanes levels were standardized to the levels of urinary creatinine. It was measured applying the enzyme method Creatinine plus version 2 (CREP2) (Cobas Integra, Roche).

\section{Titration}

Continuous positive pressure was used for all patients on the titration night. Once apneas were eliminated, the pressure was then increased to eliminate hypopneas and snoring. Pressure determination was as follows: the lowest pressure required to eliminate apneas was used for expiratory PAP (EPAP) level; the pressure required to eliminate hypopneas and snoring was used for inspiratory PAP (IPAP).

\section{Adherence to treatment}

All patients assigned to BiPAP were instructed to use it at home every night for at least 4 hours. Adherence was determined by a monthly download of device memory. Adherence was mainly expressed as average hours of night use in the 90 nights of the study period. Patients were considered compliant if they used the BiPAP for an average of 4 hours or more per night and 5 days or more per week.

\section{Statistical methods}

Data are presented as mean \pm standard deviation (SD). The Kolmogorov-Smirnov test was used for the detection of the distribution of variables. Continuous data was compared by analysis of variance (ANOVA) or the Mann-Whitney $\mathrm{U}$ test. Categorical data were compared by the Chi-square or Kruskal-Wallis tests. To assess the association between continuous variables, bivariate correlation analysis was used. To analyze which variables were associated with systolic dysfunction, univariate analyses were performed separately for each variable using binary logistic regression analysis. A $P$-value of less than 0.05 was considered as statistically significant. Statistical analysis was performed with a standard statistical program package (SPSS version 14.0, IBM Corporation, Armonk, NY, USA).

\section{Results}

\section{General characteristics of the patients with OSA and mild systolic dysfunction}

Table 1 details participant characteristics. Nineteen participants (18 men; one woman) received noninvasive ventilation in addition to their standard pharmacotherapy. Eleven patients (eleven men) remained on pharmacotherapy only. There were no significant differences between the two groups 
Table I Basic characteristics of the patients

\begin{tabular}{|c|c|c|c|}
\hline & BiPAP group (19) & Standard therapy (I I) & Control group (15) \\
\hline \multicolumn{4}{|l|}{ Anthropometric characteristics } \\
\hline \multirow[t]{2}{*}{ Age (years) } & $55.4 \pm 10.3$ & $53.15 \pm 7.68$ & $49.75 \pm 6.78$ \\
\hline & & & $P=0.623 * * *$ \\
\hline Male/female & $18 / 1$ & $11 / 0$ & $12 / 3$ \\
\hline \multirow[t]{2}{*}{$\operatorname{BMI}\left(\mathrm{kg} / \mathrm{m}^{2}\right)$} & $41.05 \pm 5.95$ & $39.06 \pm 6.92$ & $38.06 \pm 7.57$ \\
\hline & & & $P=0.485^{* * *}$ \\
\hline \multirow[t]{2}{*}{ Waist circumference $(\mathrm{cm})$} & $134.6 \pm 13.32$ & $130.3 \pm 16.29$ & $132.16 \pm 19.76$ \\
\hline & & & $P=0.42 I^{* * *}$ \\
\hline Smokers (current:former:nonsmoker) & $12: 6: 1$ & $5: 4: 2$ & $12: 2: 1$ \\
\hline \multicolumn{4}{|l|}{ Sleep study characteristics } \\
\hline Mild-moderate OSA & $3 / 19(16 \%)$ & $2 / 11(18 \%)$ & 0 \\
\hline Severe OSA & $16 / 19(84 \%)$ & $9 / 11$ (82\%) & $15 / 15(100 \%)$ \\
\hline \multirow[t]{2}{*}{$\mathrm{AHI}$ (events/hour) } & $50.93 \pm 25.4$ & $49.14 \pm 28.3$ & $65.94 \pm 30.58$ \\
\hline & & & $P=0.32 I^{* * *}$ \\
\hline \multirow[t]{2}{*}{ Sleep duration (min) } & $211 \pm 21.6$ & $209 \pm 45.9$ & $203.5 \pm 44.3$ \\
\hline & & & $P=0.087^{* * *}$ \\
\hline \multicolumn{4}{|l|}{ Average desaturation index (\%) } \\
\hline \multirow[t]{2}{*}{ Time $\mathrm{SpO}_{2}<90 \%$ (sleep time) } & $79.43 \pm 28.9$ & $56.35 \pm 37.8$ & $50.43 \pm 23.41$ \\
\hline & & & $P=0.114^{* * *}$ \\
\hline \multicolumn{4}{|l|}{ Lipid profiles } \\
\hline \multirow[t]{2}{*}{ HDL (mmol/L) } & $1.20 \pm 0.29$ & $1.35 \pm 0.38$ & $\mathrm{I} .3 \mathrm{I} \pm 0.4 \mathrm{I}$ \\
\hline & & & $P=0.912 * * *$ \\
\hline \multirow[t]{2}{*}{$\mathrm{LDL}(\mathrm{mmol} / \mathrm{L})$} & $2.74 \pm 0.75$ & $3.38 \pm 1.06$ & $3.25 \pm 1.05$ \\
\hline & & & $P=0.428^{* * *}$ \\
\hline \multirow[t]{2}{*}{ VLDL (mmol/L) } & $0.94 \pm 0.53$ & $0.83 \pm 0.34$ & $0.81 \pm 0.25$ \\
\hline & & & $P=0.781 * * *$ \\
\hline \multirow[t]{2}{*}{ Total cholesterol $(\mathrm{mmol} / \mathrm{L})$} & $4.86 \pm 1.03$ & $5.57 \pm 0.99$ & $5.39 \pm 1.28$ \\
\hline & & & $P=0.613^{* * *}$ \\
\hline \multirow[t]{2}{*}{ Triglycerides (mmol/L) } & $1.81 \pm 0.64$ & $1.83 \pm 0.76$ & $1.83 \pm 0.56$ \\
\hline & & & $P=0.345^{* * *}$ \\
\hline \multirow[t]{2}{*}{ Glucometabolic markers } & $15.60 \pm 4.48$ & $12.13 \pm 4.16$ & $3.5 \pm 4.58$ \\
\hline & & & $P=0.000 * * *$ \\
\hline \multirow[t]{2}{*}{ Immunoreactive insulin (mUl/mL) } & $18.47 \pm 10.65$ & $15.3 \pm 8.67$ & $19.46 \pm 14.26$ \\
\hline & $P=0.316^{*}$ & $P=0.229 * *$ & $P=0.15 I^{* * *}$ \\
\hline \multirow[t]{2}{*}{ HOMA index } & $4.18 \pm 2.37$ & $3.43 \pm 2.48$ & $6.01 \pm 7.21$ \\
\hline & & & $P=0.177 * * *$ \\
\hline \multirow[t]{2}{*}{$\mathrm{HbA}_{\mathrm{IC}}$} & $6.59 \pm 1.31$ & $5.92 \pm 0.63$ & $6.04 \pm 0.82$ \\
\hline & $P=0.253^{*}$ & $P=0.103 * *$ & $P=0.210 * * *$ \\
\hline \multicolumn{4}{|l|}{ Biomarkers } \\
\hline \multirow[t]{2}{*}{ Isorpostanes (pg/ $\mu \mathrm{L} c r n)$} & $0.164 \pm 0.09$ & $0.125 \pm 0.05$ & $0.049 \pm 0.02$ \\
\hline & & $P=0.04 I^{* *}$ & $P=0.003^{* * *}$ \\
\hline NT-pro-BNP (pmol/L) & $51.75 \pm 46.3$ & $39.12 \pm 8.76$ & - \\
\hline
\end{tabular}

Notes: *Mann-Whitney comparison of BiPAP versus standard therapy; **Mann-Whitney comparison of standard therapy versus control; ***Mann-Whitney comparison of BiPAP versus control.

Abbreviations: BMI, body mass index; BiPAP, bilevel positive airway pressure; HDL, high-density lipoprotein; HOMA, Homeostasis Model Assessment; LDL, low-density lipoprotein; NT-pro-BNP, N-terminal prohormone of brain natriuretic peptide; OSA, obstructive sleep apnea; VLDL, very low-density lipoprotein.

regarding their anthropometric characteristics - age, weight, and waist circumference.

The systolic dysfunction was due to arterial hypertension in $54 \%$ of the patients in the BiPAP group. In $36 \%$ of them it was as a result of ischemic heart disease. The etiology of the disease was similar in the group that remained on pharmacological treatment only.
Patients with both treatment modalities had almost similar 24-hour profiles of systolic and diastolic blood pressure (Table 2). All patients had been receiving optimal doses of angiotensin-converting enzyme inhibitors, diuretics, and beta-blockers according to the guidelines for treatment of hypertension and early systolic dysfunction (data presented in Table 1). 
Table 2 Echocardiographic and hemodynamic characteristics of patients

\begin{tabular}{|c|c|c|c|}
\hline & BiPAP group (19) & Standard therapy (I I) & Control group (15) \\
\hline \multicolumn{4}{|l|}{ Echocardiographic characteristics } \\
\hline LVFS (\%) & $26.26 \pm 4.12$ & $25.14 \pm 3.09$ & $32.75 \pm 4.46$ \\
\hline $\mathrm{EF}(\%)$ & $45.64 \pm 5.48$ & $45.87 \pm 6.87$ & $60.37 \pm 6.30$ \\
\hline Septum (mm) & $13.75 \pm 2.1$ & $11.82 \pm 2.2$ & $12.68 \pm 1.53$ \\
\hline $\mathrm{PW}(\mathrm{mm})$ & $13.29 \pm 1.8$ & $12.76 \pm 1.9$ & $12.66 \pm 1.63$ \\
\hline \multicolumn{4}{|l|}{ Blood pressure characteristics } \\
\hline Diurnal systolic blood pressure $(\mathrm{mmHg})$ & $134.66 \pm 8.17$ & $142.3 \pm 9.48$ & $136.28 \pm 13.81$ \\
\hline Diurnal diastolic blood pressure $(\mathrm{mmHg})$ & $80.01 \pm 9.31$ & $81.3 \pm 9.82$ & $82.8 \pm 8.89$ \\
\hline Nocturnal systolic blood pressure $(\mathrm{mmHg})$ & $126.05 \pm 9.63$ & $109.2 \pm 8.12$ & $121.85 \pm 10.57$ \\
\hline Nocturnal diastolic blood pressure $(\mathrm{mmHg})$ & $78.8 \pm 9.41$ & $67.3 \pm 9.65$ & $73.02 \pm 7.33$ \\
\hline \multicolumn{4}{|l|}{ Cardiomyopathy } \\
\hline Ischemic/non-ischemic & $8 / 19(42 \%)$ & $6 / 11(54 \%)$ & $1 / 15(1 \%)$ \\
\hline Diabetics & $5 / 19(25 \%)$ & $4 / 11(27 \%)$ & $2 / 15(13 \%)$ \\
\hline Impaired glucose tolerance & $5 / 19(25 \%)$ & - & $8 / 15(53 \%)$ \\
\hline Normal glucose metabolism & $9 / 18$ (50\%) & $7 / 11(63 \%)$ & $5 / 15(34 \%)$ \\
\hline \multicolumn{4}{|l|}{ Treatment } \\
\hline ACEI & $18 / 19(94 \%)$ & $9 / 11(81 \%)$ & $13 / 15(87 \%)$ \\
\hline Beta blockers & $12 / 19(63 \%)$ & $7 / 11(63 \%)$ & $10 / 15(67 \%)$ \\
\hline Diuretics & $17 / 19(89 \%)$ & $8 / 11$ (72\%) & $9 / 15(60 \%)$ \\
\hline Statins & $1 / 19(5 \%)$ & $3 / 11(27.2 \%)$ & $4 / 15(26 \%)$ \\
\hline
\end{tabular}

Abbreviations: ACEl, angiotensin-converting-enzyme inhibitor; BiPAP, bilevel positive airway pressure; EF, ejection fraction; LVFS, left ventricle fractional shortening; PW, pulsed wave.

Fifty percent of the patients in the BiPAP group had dysglycemia (diabetes $25 \%$; impaired glucose tolerance $25 \%$ ). In the group that remained on standard treatment only $27 \%$ were diabetics, the rest $(73 \%)$ did not have any impairments in their glucose metabolism (Table 2).

\section{Sleep study characteristics of the patients with OSA and mild systolic dysfunction}

In comparing the groups of treatment modality according to their sleep study characteristics, no large discrepancies could be observed. In the BiPAP group, 84\% (16/19) had severe apnea. The percentage was nearly the same in the group on standard therapy: $82 \%(9 / 11)$. The duration of sleep and AHI indexes were also comparable. The time with $\mathrm{SpO}_{2}<90 \%$ however, was significantly longer in the BiPAP group (79\% versus $56 \%$ ), but not of statistical significance (Table 1).

\section{General characteristics of the control group}

The anthropometric characteristics of the control group (with preserved EF) did not differ significantly from those of the patients with mild systolic dysfunction (Table 1). The mean age of the group was $49.75 \pm 6.78$ years. The average body mass index (BMI) was $38.06 \pm 7.57$. All patients in the control group were treated for hypertension. Sixty-six percent of the patients had dysglycemia (13\% had diabetes and 53\% had impaired glucose tolerance). All patients had severe apnea. The average AHI was $65.94 \pm 30.58$ events/hour.

\section{Comparison between biomarkers of oxidative stress in OSA patients with preserved systolic function and mild systolic dysfunction}

Urinary isorpostanes levels in OSA patients with mild systolic dysfunction were compared to those in the control group with preserved EF. As shown in Table 3, urinary isorpostanes levels were higher in patients with systolic dysfunction $(P=0.023)$. The two groups did not differ significantly except for the average desaturation index. However, even after adjustment for average desaturation index, the difference in urinary isorpostanes levels between the two groups remained significant $(P=0.042)$. Urinary isorpostanes correlated to none of the anthropometric, metabolic, or sleep study parameters except for the average desaturation index $(P=0.043$, Table 4). To further test whether oxidative stress is associated with systolic dysfunction, a univariate regression analysis was performed. In the univariate analysis, none of the markers (Table 5) were associated with systolic dysfunction.

\section{The effects of BiPAP on biomarkers of hemodynamic and oxidative stress in patients with systolic dysfunction}

All patients with systolic dysfunction were followed up and their urinary levels of isorpostanes were measured at baseline and at the third month. Only in patients on BiPAP was there a statistically significant decrease in urinary isorpostanes 
Table 3 Clinical parameters and biomarkers of oxidative stress in patients with systolic dysfunction and in the control group

\begin{tabular}{|c|c|c|}
\hline & $\begin{array}{l}\text { Patients with systolic } \\
\text { dysfunction }\end{array}$ & Controls \\
\hline \multicolumn{3}{|l|}{ Anthropometrics } \\
\hline Age (years) & $54.5 \pm 8.2$ & $\begin{array}{l}49.75 \pm 6.78 \\
P=0.172\end{array}$ \\
\hline BMI $\left(\mathrm{kg} / \mathrm{m}^{2}\right)$ & $40.31 \pm 5.12$ & $\begin{array}{l}38.06 \pm 7.57 \\
P=0.262\end{array}$ \\
\hline \multicolumn{3}{|l|}{ Glucometabolic } \\
\hline IRI (mU/L) & $17.31 \pm 9.4$ & $\begin{array}{l}19.46 \pm 14.26 \\
P=0.845\end{array}$ \\
\hline $\begin{array}{l}\text { Fasting glucose } \\
(\mathrm{mmol} / \mathrm{L})\end{array}$ & $6.24 \pm 2.71$ & $\begin{array}{l}6.01 \pm 2.1 \\
P=0.765\end{array}$ \\
\hline $\mathrm{HbA}_{1 \mathrm{C}}$ & $6.34 \pm 0.82$ & $\begin{array}{l}6.04 \pm 0.82 \\
P=0.259\end{array}$ \\
\hline \multicolumn{3}{|l|}{ Sleep characteristics } \\
\hline Sleep duration & 210.26 & \\
\hline $\mathrm{AHI}$ & $50.27 \pm 26.1$ & $\begin{array}{l}65.94 \pm 30.58 \\
P=0.274\end{array}$ \\
\hline Average desat index & $14.33 \pm 4.48$ & $\begin{array}{l}3.5 \pm 4.58 \\
P=0.000\end{array}$ \\
\hline $\mathrm{SpO}_{2}<90 \%$ & $70.94 \pm 31.1$ & $\begin{array}{l}50.43 \pm 23.4 I \\
P=0.180\end{array}$ \\
\hline \multicolumn{3}{|l|}{ Oxidative stress markers } \\
\hline Isorpostanes (pg/mL) & $0.149 \pm 0.09$ & $\begin{array}{l}0.049 \pm 0.02 \\
P=0.023\end{array}$ \\
\hline
\end{tabular}

Abbreviations: $\mathrm{AHI}$, apnea-hypopnea index; $\mathrm{BMI}$, body mass index; IRI, immunoreactive insulin.

levels (Table 6). The plasma levels of NT-pro-BNP were followed up in $89 \%$ of the BiPAP patients and $72 \%$ of the control group. In both groups plasma levels decreased, but did not reach statistical significance.

Table 4 Correlations between clinical parameters and biomarkers of oxidative stress - isorpostanes in patients with systolic dysfunction

\begin{tabular}{ll}
\hline & Isorpostanes \\
\hline Anthropometrics & \\
Age (years) & $P=0.923$ \\
BMI $\left(\mathrm{kg} / \mathrm{m}^{2}\right)$ & $P=0.649$ \\
Smoking status & $P=0732$ \\
Glucometabolic & \\
IRI (mU/L) & $P=0.638$ \\
$\mathrm{HbA}$ & $P=0.326$ \\
Sleep characteristics & \\
Sleep duration (minutes) & $P=0.074$ \\
AHI & $P=0.274$ \\
Average desaturation index & $P=0.043$ \\
SpO $_{2}<90 \%$ & $P=0.392$ \\
\hline
\end{tabular}

Abbreviations: AHI, apnea-hypopnea index; BMI, body mass index; IRI, immunoreactive insulin.
Table 5 Univariate regression analysis for predictors of left systolic dysfunction

\begin{tabular}{|c|c|c|}
\hline & $P$-value & $\mathbf{R}$ \\
\hline Age (years) & 0.632 & 0.001 \\
\hline Sex & 0.523 & 0.004 \\
\hline BMI $\left(\mathrm{kg} / \mathrm{m}^{2}\right)$ & 0.101 & 0.007 \\
\hline $\mathrm{AHI}$ (events/hour) & 0.065 & 0.011 \\
\hline Average desaturation (\%) & 0.072 & 0.013 \\
\hline Time of sleep $\mathrm{SpO}_{2}<90 \%$ (minutes) & 0.217 & 0.003 \\
\hline $\mathrm{HbA}_{\mathrm{IC}}$ & 0.063 & 0.0032 \\
\hline IRI (mU/L) & 0.149 & 0.008 \\
\hline Isorpostanes $(\mathrm{pg} / \mathrm{mL})$ & 0.092 & 0.023 \\
\hline Systolic blood pressure $(\mathrm{mmHg})$ & 0.196 & 0.001 \\
\hline Diastolic blood pressure $(\mathrm{mmHg})$ & 0.382 & 0.017 \\
\hline Diabetes & 0.181 & 0.024 \\
\hline Coronary artery disease & 0.442 & 0.023 \\
\hline Hypertension & 0.487 & 0.032 \\
\hline ACEI & 0.312 & 0.008 \\
\hline Beta blockers & 0.128 & 0.007 \\
\hline Diuretics & 0.233 & 0.023 \\
\hline Statins & 0.061 & 0.012 \\
\hline
\end{tabular}

Abbreviations: ACEl, angiotensin-converting-enzyme inhibitor; $\mathrm{AHI}$, apneahypopnea index; BMI, body mass index; IRI, immunoreactive insulin.

\section{Discussion}

\section{OSA, chronic intermittent hypoxia $(\mathrm{ClH})$,} and oxidative stress in heart failure patients

$\mathrm{CIH}$ that accompanies OSA is generally accepted as a unique pathophysiological mechanism, responsible for oxidative stress, inflammation, and cardiovascular damage. Experimental evidence indicates that $\mathrm{CIH}$ is a unique physiological state with potentially adaptive and maladaptive consequences for cardio-respiratory homeostasis. Now, numerous studies have shown that oxidative stress is the main mechanism of cardiac ischemia/reperfusion (I/R) injury. ${ }^{20-22}$ Because there is a resemblance between the patterns of $\mathrm{CIH}$ associated with OSA and I/R injury, potential mechanisms of oxidative stress in OSA have been postulated to be directly related to $\mathrm{CIH}$ in a manner similar to I/R injury or indirectly via inflammatory response.

Most recent studies in animal models of $\mathrm{CIH}$ as well as in OSA patients confirm that OSA is associated with oxidative stress, which generally correlates with the severity of sleep apnea. ${ }^{16,23} \mathrm{CIH}$-provoked mild and transient oxidative stress can induce adaptation, but severe and persistent $\mathrm{CIH}$ may provoke maladaptation as in OSA patients if untreated. As oxidative imbalance has been accepted as a trigger for cardiac dysfunction, the early detection of increased oxidative stress in OSA patients is of importance for risk stratification and strict control regarding CPAP compliance and treatment. 
Table 6 Baseline and third month isorpostanes and NT-pro-BNP

\begin{tabular}{llllll}
\hline & BiPAP group & & \multicolumn{2}{l}{ Standard treatment } \\
\cline { 2 - 3 } & Baseline & Third month & & Baseline & Third month \\
\hline NT-pro-BNP (pmol/L) & $51.75 \pm 46.3$ & $7.45 \pm 6.12$ & $39.12 \pm 8.76$ & $11.4 \pm 7.12$ \\
Isorpostanes & & $P=0.066$ & & $P=0.235$ & $0.097 \pm 0.03$ \\
& $0.164 \pm 0.09$ & $0.098 \pm 0.05$ & & $0.125 \pm 0.05$ & $P=0.262$ \\
\hline
\end{tabular}

Abbreviations: BiPAP, bilevel positive airway pressure; NT-pro-BNP, N-terminal prohormone of brain natriuretic peptide.

\section{Isorpostanes - markers for oxidative stress in OSA}

F2-isorpostanes are products of the free radical catalyzed peroxidation of arachidonic acid in biological membranes and validated markers of oxidative stress in vivo. ${ }^{24}$ Increased urinary excretion or plasma concentrations of F2-isorpostanes have been observed in many conditions (smoking, insulin resistance, diabetes), ${ }^{25-28}$ where their increase is associated with endothelial dysfunction, myocardial apoptosis, gene expression modification, and cardiac remodeling. ${ }^{29}$

In our study we investigated the levels of oxidative stress, measured by urinary isorpostanes concentration. Highly sensitive mass spectrometry was used for precise measurement. Urinary isorpostanes levels in OSA patients with mild systolic dysfunction (EF - 40\%-45\%) were compared to those with preserved EF. The design of the study was planned to determine if urinary isorpostanes levels could serve as biomarkers for increased risk of oxidative stress in OSA. In our study group, patients shared common risk factors for systolic dysfunction and had moderate to severe OSA. We found that urinary isorpostanes were significantly higher in OSA patients with mild systolic dysfunction in comparison to those with preserved EF. However, a univariate regression analysis determined that isorpostanes were not associated with systolic dysfunction, probably due to the small number of patients. Urinary isorpostanes concentration correlated best to the average desaturation index and did not show associations with AHI.

Our findings are similar to those of Monneret et a ${ }^{14}$ who reported that urinary isorpostanes are high in otherwise healthy OSA patients in comparison to carefully matched controls and are indicative of carotid-intima media thickness even in the absence of a functional vessel impairment. Similar to our results, they showed that urinary isorpostanes are markers of oxidative stress in OSA patients that correlate best to $\mathrm{AHI}$ and the desaturation index. ${ }^{14}$

Both studies point to the fact that urinary isorpostanes could serve as reliable markers of chronic intermittent hypoxia and oxidative stress. They may find clinical usefulness in the detection of patients before overt cardiovascular damage develops.

\section{Noninvasive ventilation and oxidative stress in OSA patients with heart failure}

Noninvasive ventilation is the standard treatment for patients with obstructive sleep apnea. Though the hemodynamic effects of PAP ventilation are well described, it is still disputable whether PAP ventilation diminishes the imbalance between increased reactive oxygen species generation and endogenous antioxidant pools. As oxidative stress imbalance contributes to heart failure progression, its abolishment is attractive for prophylactic and therapeutic intervention of OSA.

In our study, we aimed to assess LV systolic functions in patients with moderate to severe OSA treated for 3 months either with BiPAP and pharmacotherapy, or pharmacotherapy alone. Blood pressure profiles, anthropometric risk factors, and other cardiovascular risk factors were similar in both groups. There were no significant differences between the groups in any of the echocardiographic parameters examined. However, urinary isorpostanes decreased significantly only in patients with noninvasive ventilation. Their fall preceded the decrease of NT-pro-BNP (51.47 versus 7.93, $P=0.066$ ), a well validated marker of hemodynamic stress. Though speculative, we can hypothesize that oxidative stress in OSA patients could be easier manipulated in patients with systolic dysfunction where large hemodynamic abnormalities are still absent.

\section{Limitations}

The results of the study are best related to patients with severe OSA ( $>60 \%$ of the patients had AHI $>30$ events/hour), extreme obesity (BMI $>38 \mathrm{~kg} / \mathrm{m}^{2}$ ), and predominantly men. The cross sectional characteristics of the study and the small number of patients do not allow for a cause-effect analysis regarding levels of oxidative stress and cardiac damage. 


\section{Conclusion}

According to our findings, urinary isorpostanes correlate best to the average desaturation index in OSA, which suggests that they are reliable biomarkers for $\mathrm{CIH}$ and oxidative stress. They are increased in OSA patients with mild systolic dysfunction in comparison to those with preserved EF, which, if confirmed in larger studies, may be of clinical application for the early detection of patients at risk for cardiovascular damage.

Considering our results, urinary isorpostanes could be modified by BiPAP therapy. This could be of therapeutic utility if the result holds in larger and longer clinical trials. Isorpostanes may help in the monitoring of the effect of BiPAP therapy, as well as allow for the supplementation of antioxidants to balance the redox status in OSA patients with systolic dysfunction.

\section{Acknowledgments}

This work is supported by the Scientific Grant of the Medical University of Sofia, 2011; Contract 15/Project 27. This work was performed under the benevolence of the Head of the Medical University and with the kind collaboration of the Department of Medical Chemistry and Biochemistry, Laboratory of Synthesis and Analysis of Bioactive Substances, and The Central Clinical Laboratory.

\section{Disclosure}

The authors report no conflicts of interest in this work.

\section{References}

1. Sin DD, Fitzgerald F, Parker JD, Newton G, Floras JS, Bradley TD. Risk factors for central and obstructive sleep apnea in 450 men and women with congestive heart failure. Am J Respir Crit Care Med. 1999;160(4):1101-1106.

2. Javaheri S, Parker TJ, Liming JD, et al. Sleep apnea in 81 ambulatory male patients with stable heart failure. Types and their prevalences, consequences, and presentations. Circulation. 1998;97(21):2154-2159.

3. Malhotra A, White DP. Obstructive sleep apnoea. Lancet. 2002; 360(9328):237-245.

4. Punjabi NM, Shahar E, Redline S, Gottlieb DJ, Givelber R, Resnick HE; Sleep Heart Health Study Investigators. Sleep-disordered breathing, glucose intolerance, and insulin resistance: the Sleep Heart Health Study. Am J Epidemiol. 2004;160(6):521-530.

5. McArdle N, Hillman D, Beilin L, Watts G. Metabolic risk factors for vascular disease in obstructive sleep apnea: a matched controlled study. Am J Respir Crit Care Med. 2007;175(2):190-195.

6. Marin JM, Carrizo SJ, Vicente E, Agusti AG. Long-term cardiovascular outcomes in men with obstructive sleep apnoea-hypopnoea with or without treatment with continuous positive airway pressure: an observational study. Lancet. 2005;365(9464):1046-1053.

7. Shamsuzzaman AS, Gersh BJ, Somers VK. Obstructive sleep apnea: implications for cardiac and vascular disease. JAMA. 2003;290(14): 1906-1914.

8. Lavie L. Obstructive sleep apnoea syndrome - an oxidative stress disorder. Sleep Med Rev. 2003;7(1):35-51.
9. Lavie L, Lavie P. Molecular mechanisms of cardiovascular disease in OSAHS: the oxidative stress link. Eur Respir J. 2009;33(6): 1467-1484

10. Harrison D, Griendling K, Landmesser U, Hornig B, Drexler H. Role of oxidative stress in atherosclerosis. Am J Cardiol. 2003;91(3A): 7A-11A.

11. Dhalla NS, Temsah RM, Netticadan T. Role of oxidative stress in cardiovascular diseases. J Hypertens. 2000;18(6):655-673.

12. Nourooz-Zadeh J. Key issues in F2-isoprostane analysis. Biochem Soc Trans. 2008;36(Pt 5):1060-1065.

13. Morrow JD, Minton TA, Badr KF, Roberts LJ 2nd. Evidence that the F2-isoprostane, 8-epi-prostaglandin F2alpha, is formed in vivo. Biochim Biophys Acta. 1994;1210:244-8.

14. Monneret D, Pepin JL, Godin-Ribuot D, et al. Association of urinary 15-F2t-isoprostane level with oxygen desaturation and carotid intimamedia thickness in nonobese sleep apnea patients. Free Radic Biol Med. 2010;48(4):619-625.

15. Marin JM, Agusti A, Villar I, et al. Association between treated and untreated obstructive sleep apnea and risk of hypertension. JAMA. 2012;307(20):2169-2176.

16. Laaban JP, Pascal-Sebaoun S, Bloch E, Orvoën-Frija E, Oppert JM, Huchon G. Left ventricular systolic dysfunction in patients with obstructive sleep apnea syndrome. Chest. 2002;122(4):1133-1138.

17. Alchanatis M, Tourkohoriti G, Kosmas EN, et al. Evidence for left ventricular dysfunction in patients with obstructive sleep apneoa syndrome. Eur Respir J. 2002;20(5):1239-1245.

18. Littner M, Kushida CA, Anderson WM, et al; Standards of Practice Committee of the American Academy of Sleep Medicine. Practice parameters for the role of actigraphy in the study of sleep and circadian rhythms: an update for 2002. Sleep. 2003;26(3):337-341.

19. Lang RM, Badano LP,Tsang W, etal;American Society of Echocardiography; European Association of Echocardiography. EAE/ASE recommendations for image acquisition and display using three-dimensional echocardiography. JAm Soc Echocardiogr. 2012;25(1): 3-46.

20. Downey JM, Cohen MV. Reducing infarct size in the setting of acute myocardial infarction. Prog Cardiovasc Dis. 2006;48(5):363-371.

21. Ichas F, Mazat JP. From calcium signaling to cell death: two conformations for the mitochondrial permeability transition pore. Switching from low- to high-conductance state. Biochim Biophys Acta. 1998; 1366(1-2):33-50.

22. Hung LM, Chen JK, Lee RS, Liang HC, Su MJ. Beneficial effects of astringinin, a resveratrol analogue, on the ischemia and reperfusion damage in rat heart. Free Radic Biol Med. 2001;30(8):877-883.

23. Khayat R, Patt B, Hayes D Jr. Obstructive sleep apnea: the new cardiovascular disease. Part I: obstructive sleep apnea and the pathogenesis of vascular disease. Heart Fail Rev. 2009;14(3):143-153.

24. Morrow JD, Hill KE, Burk RF, Nammour TM, Badr KF, Roberts LJ 2nd. A series of prostaglandin F2-like compounds are produced in vivo in humans by a non-cyclooxygenase, free radical-catalyzed mechanism. Proc Natl Acad Sci U S A. 1990;87(23):9383-9387.

25. Davi G, Guagnano MT, Ciabattoni G, et al. Platelet activation in obese women: role of inflammation and oxidant stress. JAMA. 2002;288(16): 2008-2014.

26. Davi G, Ciabattoni G, Consoli A, et al. In vivo formation of 8-isoprostaglandin f2alpha and platelet activation in diabetes mellitus: effects of improved metabolic control and vitamin E supplementation. Circulation 1999;99(2):224-229.

27. Minuz P, Patrignani P, Gaino S, et al. Increased oxidative stress and platelet activation in patients with hypertension and renovascular disease. Circulation. 2002;106(22):2800-2805.

28. Davi G, Alessandrini P, Mezzetti, A, et al. In vivo formation of 8 epiprostaglandin F2 alpha is increased in hypercholesterolemia. Arterioscler Thromb Vasc Biol. 1997;17(11):3230-3235.

29. Basarici I, Altekin RE, Demir I, Yilmaz H. Associations of isorpostanes-related oxidative stress with surrogate subclinical indices and angiographic measures of atherosclerosis. Coron Artery Dis. 2007;18(8):615-620. 
30. Lavie L, Vishnevsky A, Lavie P. Evidence for lipid peroxidation in obstructive sleep apnea. Sleep. 2004;27(1):123-128.

31. Svatikova A, Wolk R, Lerman L, et al. Oxidative stress in obstructive sleep apnoea. Eur Heart J. 2005;26(22):2435-2439.
32. Oztürk L, Mansour B, Yüksel M, Yalçin AS, Celikoğlu F, Gökhan N. Lipid peroxidation and osmotic fragility of red blood cells in sleep-apnea patients. Clin Chim Acta. 2003;332(1-2):83-88.

\section{Publish your work in this journal}

Research Reports in Clinical Cardiology is an international, peerreviewed, open access journal publishing original research, reports, editorials, reviews and commentaries on all areas of cardiology in the clinic and laboratory. The manuscript management system is completely online and includes a very quick and fair peer-review system.
Visit http://www.dovepress.com/testimonials.php to read real quotes from published authors.

\footnotetext{
Submit your manuscript here: http://www.dovepress.com/research-reports-in-clinical-cardiology-journal
} 